\title{
Better Ventilator Settings Using a Computerized Clinical Tool
}

\author{
Sidharth Bagga MD, Dalton E Paluzzi, Christine Y Chen MD, Jeffrey M Riggio MD, \\ Manjula Nagaraja MD, Paul E Marik MD, and Michael Baram MD
}

\begin{abstract}
BACKGROUND: The Acute Respiratory Distress Syndome (ARDS) Network low tidal volume $\left(\mathrm{V}_{\mathrm{T}}\right)$ trial paved the ground for mechanically ventilating ARDS patients with a $V_{T}$ of $6 \mathrm{~mL} / \mathrm{kg}$ ideal body weight (IBW). Although there is no consensus that a low $V_{T}$ is advantageous in non-ARDS patients, it is accepted that high $\mathbf{V}_{T}$ should be avoided. Because compliance rates with ventilator recommendations are $30 \%$, there is a need for process improvement. We postulated that a computerized screen prompt that recommended $V_{T}$ based on height would improve compliance with low $V_{T}$. During ventilator order entry, the computerized decision tool prompts the clinician and encourages ventilation of patients at $8 \mathrm{~mL} / \mathrm{kg}$ IBW, and $6 \mathrm{~mL} / \mathrm{kg}$ IBW for patients with ARDS. METHODS: A retrospective review was performed on patients who required volume controlled mechanical ventilation over a 3-y period. Subjects were chosen randomly from the respiratory records of 6 different ICUs at a single tertiary care academic center. Half of the charts selected were before intervention of on-screen prompt, and the other half were after implementation of the computerized decision tool. RESULTS: The initial set $V_{T}$ ranged from 6.26 to $13.45 \mathrm{~mL} / \mathrm{kg} \mathrm{IBW}$, with a mean of $8.92 \mathrm{~mL} / \mathrm{kg}$. After implementation of the on-screen prompt, mean $V_{T}$ decreased by $0.84 \mathrm{~mL} / \mathrm{kg}$ to $8.07 \mathrm{~mL} / \mathrm{kg}(P=.001)$ with a lower range of $4.73-11.56 \mathrm{~mL} / \mathrm{kg}$ IBW. We also noted a significant decrease in the number of subjects placed on an initial $V_{T}>10 \mathrm{~mL} / \mathrm{kg}$ IBW from $20 \%$ to $4 \%$ $(P=.003)$. CONCLUSIONS: A computerized clinical decision tool with the preferred initial $V_{T}$ settings based on the patients' sex and height is a safe and reliable way to increase low $V_{T}$ strategy compliance across multiple ICUs. Its limitations are similar to those shared by other computergenerated prompts. Key words: ARDS; computerized clinical decision support system; mechanical ventilation. [Respir Care 2014;59(8):1172-1177. (C) 2014 Daedalus Enterprises]
\end{abstract}

\section{Introduction}

Mechanical ventilation is a lifesaving intervention that allows for oxygenation and ventilation of patients while their underlying disease or clinical issues resolve. ${ }^{1}$ Changes in ventilator strategy over the last decade have decreased the harmful effects of mechanical ventilation. In the evo-

Dr Bagga, Mr Paluzzi, Dr Chen, and Drs Riggio, Nagaraja, and Baram are affiliated with the Division of Pulmonary and Critical Care, Jefferson Medical College, Philadelphia, Pennsylvania; Dr Marik is affiliated with the Division of Pulmonary and Critical Care, Eastern Virginia Medical School, Norfolk, Virginia.

None of the authors have disclosed a conflict of interest.

Dr Bagga presented a version of this paper at the 108th International Conference of the American Thoracic Society, held May 18-23, 2012, in San Francisco, California. lution of mechanical ventilation, many factors have emerged as causes of injury to the lung. In 1998, ARDSnet researchers demonstrated that limiting tidal volume $\left(\mathrm{V}_{\mathrm{T}}\right)$ in patients with diffuse lung injury improved outcomes

See the Related Editorial on Page 1310

and mortality. ${ }^{2,3}$ High $\mathrm{V}_{\mathrm{T}}$ and high plateau pressures were found to be injurious to the lung parenchyma and were associated with worse outcomes. ${ }^{4}$ The goal in treating pa-

Correspondence: Michael Baram MD, Jefferson Pulmonary Associates, 834 Walnut Street, Suite 650, Philadelphia, PA, 19017. E-mail: Michael.Baram@jefferson.edu.

DOI: $10.4187 /$ respcare.02223 
tients with respiratory failure receiving mechanical ventilation is to support the patients as their illness improves while preventing ventilator-induced lung injury. ${ }^{4,5} \mathrm{~A}$ low $\mathrm{V}_{\mathrm{T}}$ approach decreases ventilator-induced lung injury in patients without preexisting acute lung injury (ALI) and suggests that a low $\mathrm{V}_{\mathrm{T}}$ strategy is beneficial in all patients. ${ }^{6,7}$ Reasons for adopting a low $\mathrm{V}_{\mathrm{T}}$ strategy in all patients include limiting the development of delayed ALI and preventing barotrauma. However, there is no consensus on the optimal initial $\mathrm{V}_{\mathrm{T}}$ in patients without ALI. ${ }^{8}$

At our tertiary care center, pilot data showed that a large proportion of our patients were receiving an initial $\mathrm{V}_{\mathrm{T}}$ of $>10 \mathrm{~mL} / \mathrm{kg}$ ideal body weight (IBW). Poor compliance with ventilation strategy guidelines/expert opinions can be seen throughout the literature. ${ }^{9,10}$ Because the time to irreversible injury is short, prompt recognition of abnormal $\mathrm{V}_{\mathrm{T}}$ is imperative. ${ }^{3}$ Minimizing ventilator-induced lung injury is an integral part of patient care in the modern ICU. A system to provide optimal current recommendations to physicians entering the initial mechanical ventilation orders is necessary. Previous educational efforts through lectures, handouts, and taping IBW cards to each ventilator at our institution helped, but did not protect all patients from inappropriate settings. These efforts have been used at other institutions as well to improve education to reduce ARDS triggers. ${ }^{11,12}$

Recognizing the overestimation of IBW, it was postulated that computer data would help guide clinicians to safer initial $\mathrm{V}_{\mathrm{T}}$ based on patient height and sex. Implementations of expert rules have traditionally lagged years behind published trials showing efficacy. ${ }^{13,14}$ Eslami et al ${ }^{15}$ have demonstrated that their computer decision support system (CDSS) was effective in changing clinical practice for patients ventilated for $>24 \mathrm{~h}$. We hypothesized that an immediate computer-generated prompt on initial mechanical ventilation orders could improve compliance with ordering low $\mathrm{V}_{\mathrm{T}}$ strategy at the time of initial mechanical ventilation orders and reduce the risk of patients receiving $\mathrm{V}_{\mathrm{T}}>10 \mathrm{~mL} / \mathrm{kg}$ IBW.

\section{Methods}

\section{Intervention}

For nearly 2 decades, every patient on a ventilator at our institution had to have an immediate order set generated electronically by the physicians caring for the patient. The order set requires ventilator settings to be entered, as well as other standard orders such as mouth care, head of bed up, and hemodynamic monitoring.

The intervention was the addition of an on-screen prompt (Fig. 1), which was triggered with each mechanical ventilation order. The computer-generated recommendation was a standard pop-up box that was displayed every

\section{QUICK LOOK}

\section{Current knowledge}

The current standard of care for ARDS patients on mechanical ventilation includes tidal volumes $\left(\mathrm{V}_{\mathrm{T}}\right)$ of 6 $\mathrm{mL} / \mathrm{kg}$ of predicted body weight. Despite the mortality benefit, compliance with lung-protective approaches including low $\mathrm{V}_{\mathrm{T}}$ remains $<50 \%$. Methods to improve compliance are needed.

\section{What this paper contributes to our knowledge}

A computerized clinical decision support tool with the preferred initial $\mathrm{V}_{\mathrm{T}}$ settings based on gender and height proved to be a safe and reliable way to increase compliance using a lung-protective, low $\mathrm{V}_{\mathrm{T}}$ approach across multiple ICUs.

time the physician initiated or changed orders for a ventilator. The on-screen prompt displayed the patient's height, sex, IBW, and recommendations for initial $\mathrm{V}_{\mathrm{T}}$. Height and sex were already in the computer database and were previously collected as part of the admission database to help pharmacy with appropriate medication dosing. Height and weight had to be entered into the computer before entry of any hospital order. The IBW was calculated based on standard equations for ideal height to weight ratios. ${ }^{16}$ The clinicians had the option to enter any $\mathrm{V}_{\mathrm{T}}$ they wished, but they were given an actual number for the recommended $\mathrm{V}_{\mathrm{T}}$ based on the patients' recorded height and sex.

\section{Study Design}

We implemented and studied a computerized clinical decision tool, on the Centricity Enterprise (GE Healthcare, Madison, Wisconsin) platform at Thomas Jefferson University Hospital, a tertiary care academic medical center in Philadelphia, Pennsylvania, developed as an internal prompt by institutional information technologists for supporting low $\mathrm{V}_{\mathrm{T}}$ strategy. This retrospective review evaluates initial $\mathrm{V}_{\mathrm{T}}$, based on IBW, before and after a computer-generated prompt was introduced hospital-wide on October 20, 2009 (Table 1). The order entry system had been in place for over 2 decades. The only change in practice was the addition of the pop-up decision tool to prompt clinicians to use 6 or $8 \mathrm{~mL} / \mathrm{kg}$ IBW for initial ventilator settings. The prompt was a suggested $\mathrm{V}_{\mathrm{T}}$, and the physician was able to enter any $\mathrm{V}_{\mathrm{T}}$ when finalizing order. No extra training was needed because the intervention only required the user to look at the pop-up box displayed in Figure 1, and acknowledge by selecting "OK" button. All physician order entries for mechanical 


\section{Ventilator Settings With a Computerized Tool}

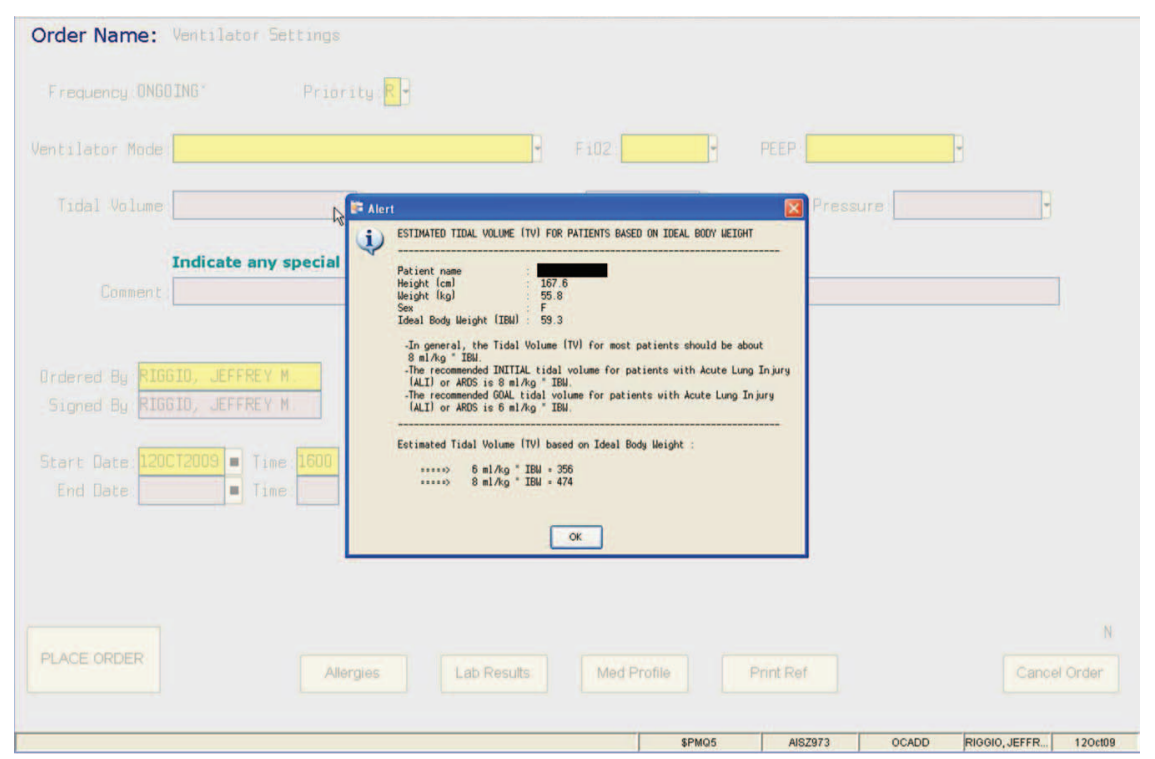

Figure 1. Screen shot of the automatic prompt displaying recommended tidal volume settings.

Table 1. Timeline of Project

\begin{tabular}{|c|c|c|}
\hline Date & Event & Effect \\
\hline Apr 2009 & $\mathrm{H} 1 \mathrm{~N} 1$ pandemic & $\begin{array}{l}\text { Death of many young } \\
\text { overweight patients }\end{array}$ \\
\hline Jun 2009 & M\&M of deaths & $\begin{array}{l}\text { Recognition of high } \mathrm{V}_{\mathrm{T}} \\
\text { on initial vent settings }\end{array}$ \\
\hline Jul 2009 & Pilot data & $\begin{array}{l}\text { Many patients with high } \\
V_{T}\end{array}$ \\
\hline Oct 2009 & Implementation of rule & $\begin{array}{l}\text { Developed a pre- and } \\
\text { post-intervention } \\
\text { group }\end{array}$ \\
\hline May 2010 & Submission to IRB & \\
\hline Jul 2010 & IRB approval collection & \\
\hline Sep 2010 & Data collection begins & $\begin{array}{l}\text { Collection of data } \\
\text { (before and after } \\
\text { prompt). }\end{array}$ \\
\hline May 2012 & ATS poster presentation & $\begin{array}{l}\text { Decision to create } \\
\text { manuscript }\end{array}$ \\
\hline $\begin{array}{l}\mathrm{M} \& \mathrm{M}=\text { morbi } \\
\mathrm{V}_{\mathrm{T}}=\text { tidal volt } \\
\text { IRB }=\text { instituti } \\
\text { ATS = Americ }\end{array}$ & $\begin{array}{l}\text { and mortality conference } \\
\text { eview board } \\
\text { oracic Society }\end{array}$ & \\
\hline
\end{tabular}

ventilation (volume or pressure limited), either initial settings or change of settings, were presented with an intervention prompt and required acknowledgment before completion of orders, but we only evaluated the initial $\mathrm{V}_{\mathrm{T}}$ orders for volume controlled modes.

\section{Study Settings}

This study was performed in an urban university hospital with approximately 1,000 beds. The decision tool was implemented in all adult (age $>18 \mathrm{y}$ ) ICUs in the hospital. The units ranged in size from 8 to 25 beds. Many patients were referral-based, and cared for by intensivists trained in their specific subspecialty. All ICUs were staffed by full-time, academic intensivists. All units have teams of house officers to help care for patients and perform electronic order entry. As in many ICUs, the house officers rotate through the ICU on a monthly basis.

\section{Subject Inclusion/Exclusion Criteria}

The study data were collected from March 2008 to July 2010. The inclusion criteria for subjects were that they were intubated, transferred to an adult ICU during the above time period, and receiving volume controlled ventilation. Subjects were picked randomly, based on respiratory care records, from all 6 different closed ICUs. The data list of ventilated subjects was provided by the respiratory therapy department. This list was divided into 2 groups: patients cared for before and after intervention. The list was then further divided by month of admission to ensure that a variety of clinicians (resident/attending physician rotation schedules were monthly) were included for review. From each month, 1 or 2 charts were randomly (simple randomization by a non-study participant) picked from the list and retrieved for analysis. In subjects who were intubated multiple times, subsequent intubations were excluded. Ultimately, data from 240 charts were recorded for sex, height, date of intubation, mode of mechanical ventilation, and initial $\mathrm{V}_{\mathrm{T}}$ recorded on respiratory records. During the first $24 \mathrm{~h}$ of intubation, a diagnosis of ARDS cannot be confirmed (while ruling out other causes of respiratory failure); therefore, this was not used as an in- 
Ventilator Settings With a Computerized Tool

Table 2. Demographics of Study Population

\begin{tabular}{lccc}
\hline \hline & $\begin{array}{c}\text { Before } \\
\text { Intervention }\end{array}$ & $\begin{array}{c}\text { After } \\
\text { Intervention }\end{array}$ & $P$ \\
\hline Average age (y) & 65.6 & 64.3 & .48 \\
Average height (cm) & 167.7 & 170.7 & .17 \\
Average IBW (kg) & 64.1 & 64.5 & .79 \\
Male (\%) & 52 & 53 & \\
& & & \\
IBW = ideal body weight & & & \\
\hline
\end{tabular}

clusion/exclusion criterion. The Thomas Jefferson University human research board approved this project.

Subject exclusion criteria were any of the following: patient was from the operating room, patient received a bone marrow transplant (because there was an insufficient sample size in the pre- and post-intervention periods), or patient was not started initially on volume control mechanical ventilation.

\section{Statistical Analyses}

Results of the study were analyzed using standard statistical techniques of paired $t$ testing to determine the difference between 2 groups. Because the data were normally distributed, and the results showed a significant number of outliers outside of standard practice, the variance ratio test ( $F$ test) was used to calculate the reduction of variance in the high outliers. Analysis of variance detects change toward the mean that is reflected as a change of the SD.

\section{Results}

The demographics of the pre- and post-intervention groups showed similar ages of 65.6 and $64.3 \mathrm{y}$, respectively $(P=.48)$. Likewise, subjects' height of $167.7 \mathrm{~cm}$ versus $170.7 \mathrm{~cm}(P=.17)$ and $\operatorname{IBW}(P=.79)$ were similar because they were based on height. ${ }^{16}$ There was no statistical difference between the groups, as can be seen in Table 2.

The initial set $\mathrm{V}_{\mathrm{T}}$ ranged from 6.26 to $13.45 \mathrm{~mL} / \mathrm{kg}$ IBW with a mean of $8.92 \mathrm{~mL} / \mathrm{kg}$ IBW. After implementation of the on-screen prompt, the mean initial set $\mathrm{V}_{\mathrm{T}}$ decreased by $0.84 \mathrm{~mL} / \mathrm{kg}$ with a new mean of $8.07 \mathrm{~mL} / \mathrm{kg} / \mathrm{IBW}$. The post-intervention range also shrank from 4.73 to $11.56 \mathrm{~mL} / \mathrm{kg}$ IBW. The changes in the $\mathrm{V}_{T}$ across the 6 ICUs are shown in Table 3. There was a large decrease in the number of subjects placed on an initial $V_{T}$ $>10 \mathrm{~mL} / \mathrm{kg}$ IBW. The rate of high $\mathrm{V}_{\mathrm{T}}$ ventilation was 24 of $120(20 \%)$, and this was reduced to 5 of $120(4 \%)$ subjects post-intervention $(P<.001)$. This reduction was seen across all the ICUs (see Table 4). Further analysis using the $\mathrm{F}$ test to compare SD (variation) of pre- and post-intervention samples found statistically significant differences overall and in specific units (surgical cardiac ICU, medical cardiac ICU, and neurological ICU).

Pre- and post-intervention results displayed in Table 3 show multiple improvements. Average $\mathrm{V}_{\mathrm{T}}$ when comparing all pre-and post-intervention groups shows improvement with $P<.001$, but 4 of the 6 individual units show improvement as well. Not only is the mean improved, but the SD became narrower for all groups. The F test shows the significance of this smaller SD. The $P$ is significant for this test in all units except for the medical ICU.

\section{Discussion}

In our retrospective review study, we noted a decrease in the initial $\mathrm{V}_{\mathrm{T}}$ after the implementation of our CDSS with on-screen prompts. The average decrease was $0.84 \mathrm{~mL} / \mathrm{kg}$. We noted a significant reduction in the number of subjects receiving a $V_{T}$ in excess of $10 \mathrm{~mL} / \mathrm{kg} I B W$. It is unclear from our study whether this reduction in $V_{T}$ had any clinical benefits; however, this was not the goal of the study. In patients with ARDS, a $V_{T}$ of $6 \mathrm{~mL} / \mathrm{kg} \mathrm{IBW}$ is considered the standard of care. It is uncertain that all patients requiring mechanical ventilation would benefit from a $\mathrm{V}_{\mathrm{T}}$ of $6 \mathrm{~mL} / \mathrm{kg} \mathrm{IBW}$; however, having a $\mathrm{V}_{\mathrm{T}}$ $>10 \mathrm{~mL} / \mathrm{kg} \mathrm{IBW}$ is likely to be harmful. ${ }^{7}$ By using computer-generated prompts, we significantly reduced the number of subjects who were overventilated.

In patients without ALI, many physicians will set the initial $\mathrm{V}_{\mathrm{T}}$ above $8 \mathrm{~mL} / \mathrm{kg}$ IBW. In patients with ARDS, a $\mathrm{V}_{\mathrm{T}}$ of $6 \mathrm{~mL} / \mathrm{kg}$ is considered preferable, and there was a linear relationship between plateau pressure and mortality. ${ }^{17}$ The ARDSnet trial is the largest and most robust study to date to compare a $\mathrm{V}_{\mathrm{T}}$ of $6 \mathrm{~mL} / \mathrm{kg}$ IBW to $12 \mathrm{~mL} / \mathrm{kg}$ IBW. ${ }^{6}$ Despite clear guidelines backed by strong randomized, controlled trials in patients documented to have ARDS, adherence to low $\mathrm{V}_{\mathrm{T}}$ remains poor. Even in centers where the original trials were performed, follow-up studies have found that only $70 \%$ of patients with ALI are ventilated with a low $\mathrm{V}_{\mathrm{T}}$ strategy. ${ }^{18}$

Due to the difficulty of creating and enforcing guidelines in management of mechanical ventilation across multiple ICUs and different disciplines, we chose to initiate a simple informative screen prompt for all physicians responsible for placing initial mechanical ventilation orders. The impact of this intervention has shown a decrease in overall $\mathrm{V}_{\mathrm{T}}$ and a dramatic reduction in the percentage of patients receiving a $\mathrm{V}_{\mathrm{T}}$ likely to be injurious. This association with decreasing initial set $\mathrm{V}_{\mathrm{T}}$ and timing of intervention is encouraging, but causal relationship cannot be established in a retrospective manner. Although our sample size was relatively small, the subjects were chosen randomly, and there was a consistent effect across all the ICUs. We therefore believe that our findings are real and 
Ventilator Settings With a Computerized Tool

Table 3. Average Initial $\mathrm{V}_{\mathrm{T}}$ by ICU Before and After Intervention With Respective Statistical Analysis

\begin{tabular}{|c|c|c|c|c|c|}
\hline \multirow{2}{*}{ Unit $(n)$} & \multicolumn{2}{|c|}{$\begin{array}{c}\text { Average } \mathrm{V}_{\mathrm{T}} \\
(\mathrm{mL} / \mathrm{kg} \mathrm{IBW}) \text { Paired } t \text { Test }\end{array}$} & \multicolumn{2}{|c|}{ Variance Ratio Test } & \multirow[b]{2}{*}{$P$} \\
\hline & $\begin{array}{l}\text { Before } \\
\text { Intervention }\end{array}$ & $\begin{array}{c}\text { After } \\
\text { Intervention }\end{array}$ & $\begin{array}{l}\text { Average change } \\
(\mathrm{mL} / \mathrm{kg} \mathrm{IBW})\end{array}$ & $P$ & \\
\hline MICU (20) & $8.73 \pm 1.69$ & $7.84 \pm 1.42$ & -0.89 & .03 & .46 \\
\hline SICU (20) & $9.32 \pm 1.51$ & $8.35 \pm 0.92$ & -0.97 & .01 & .04 \\
\hline SCCU (20) & $9.19 \pm 1.49$ & $8.01 \pm 0.80$ & -1.18 & .003 & .009 \\
\hline MCCU (20) & $8.95 \pm 1.59$ & $8.31 \pm 0.95$ & -0.64 & .07 & .03 \\
\hline NICU (20) & $8.26 \pm 1.13$ & $8.04 \pm 0.53$ & -0.22 & .17 & .002 \\
\hline NSICU (20) & $9.03 \pm 1.06$ & $7.87 \pm 0.71$ & -1.17 & $<.001$ & .09 \\
\hline Total & & & -0.84 & $<.001$ & \\
\hline $\begin{array}{l}\text { Statistical analysi } \\
\mathrm{V}_{\mathrm{T}}=\text { tidal volum } \\
\text { IBW }=\text { ideal bod } \\
\mathrm{MICU}=\text { medical } \\
\text { SICU = surgical } \\
\text { SCCU = surgical } \\
\mathrm{MCCU}=\text { medica } \\
\text { NICU = neurolog } \\
\text { NSICU = neuros }\end{array}$ & nce among all ICl & ntervention ( $\mathrm{F}$ test). & & & \\
\hline
\end{tabular}

Table 4. Number of Subjects Ventilated With Initial Orders of Greater Than $10 \mathrm{~mL} / \mathrm{kg}$ IBW Before and After Intervention

\begin{tabular}{lcc}
\hline \hline \multirow{2}{*}{ Unit $(n)$} & \multicolumn{2}{c}{$n>10 \mathrm{~mL} / \mathrm{kg}(\%)$} \\
\cline { 2 - 3 } & $\begin{array}{c}\text { Before } \\
\text { Intervention }\end{array}$ & $\begin{array}{c}\text { After } \\
\text { Intervention }\end{array}$ \\
\hline MICU (20) & $4(20)$ & $2(10)$ \\
SICU (20) & $4(20)$ & $1(5)$ \\
SCCU (20) & $7(35)$ & $1(5)$ \\
MCCU (20) & $4(20)$ & $1(5)$ \\
NICU (20) & $1(5)$ & $0(0)$ \\
NSICU (20) & $4(20)$ & $0(0)$ \\
Total $(P=0.003)$ & $24(20)$ & $5(4)$ \\
& & \\
IBW $=$ ideal body weight & & \\
MICU $=$ medical ICU & & \\
SICU $=$ surgical ICU & & \\
SCCU $=$ surgical cardiac ICU & & \\
MCCU $=$ medical cardiac ICU & & \\
NICU $=$ neurological ICU & & \\
NSICU $=$ neurosurgical ICU & & \\
\hline
\end{tabular}

represent a change in the initial ventilator setting across our entire population of patients.

There are limitations to the study, in that it was a retrospective review of a single center. We do not know how often the order entry prompt was disregarded, how accurately the heights were recorded, how respiratory therapists chose initial $\mathrm{V}_{\mathrm{T}}$ before visualizing the order, or how soon after the initial orders the changes to $V_{T}$ were made and recorded. Another limitation was the difficulty in assessing how many different physicians placed the orders and under which physician's directions (attending to resident vs resident to intern) these orders were placed. Re- gardless, many positives were seen. Physicians were forced to see IBW, inexperienced clinicians were given a tool to help guide their choices, and the prompt maintained clinicians' autonomy to vary their practice when needed. Another advantage was that this was a free intervention that resulted in a difference in practice. The prompt saved time for those clinicians who would have otherwise looked up the height, and for those who did not care to look at the prompt, it took only $1 \mathrm{~s}$ to acknowledge. This quality improvement project has another practical aspect, as better evidence evolves about ideal ventilator settings, the tool can be modified to reflect best practices and up-to-date medicine. Furthermore, because the intervention occurred without the clinicians knowing that a CDSS intervention was being developed or studied, the Hawthorne affect was also minimized.

To our knowledge, only one other group of investigators have found a benefit of CDSS in changing clinical parameters in ventilator management. ${ }^{15,19}$ Eslami et al ${ }^{15}$ found that computers were effective in instilling change. Eslami et $\mathrm{al}^{19}$ also reported that removal of the prompt resulted in decay back to previous practice, thus showing that the reminders must occur with every ventilator order change. Our intervention used a frequent reminder model: a computer prompt was shown with every order that had to do with $\mathrm{V}_{\mathrm{T}}$. In our study, we have demonstrated a significant decrease in the $\mathrm{V}_{\mathrm{T}}$ across all ICUs with a simple low-cost intervention that requires no training. The way this prompt appeared on the screen created no extra work for clinicians and helped improve adherence to guidelines. The success of this project has made this prompt a standard part of the order entry for all ventilator orders. 


\section{Ventilator Settings With a Computerized Tool}

\section{Conclusions}

An on-screen, automatic visual prompt displaying initial $\mathrm{V}_{\mathrm{T}}$ settings is an effective way to improve use of a low $\mathrm{V}_{\mathrm{T}}$ strategy. This prompt calculated ideal $\mathrm{V}_{\mathrm{T}}$ based on sex and height, and also reminded clinicians to keep $\mathrm{V}_{\mathrm{T}}$ in the ARDSnet range. This tool improved compliance across multiple ICUs. The limitations are similar to those shared by other computer-generated prompts.

\section{ACKNOWLEDGMENTS}

We thank the Jefferson Information Services \& Technology staff, in particular Peggy Beattie RN MBA and Arlene Peters.

\section{REFERENCES}

1. Pingleton SK. Complication of acute respiratory failure. Am Rev Respir Dis 1988;137(6):1463-1493.

2. Brochard L, Roudot-Thoraval F, Roupie E, Delclaux C, Chastre J, Fernandez-Mondéjar E, et al. Tidal volume reduction for prevention of ventilator-induced lung injury in acute respiratory distress syndrome. The Multicenter trial Group on Tidal Volume Reduction in ARDS. Am J Respir Crit Care Med 1998;158(6):1831-1838.

3. Halter JM, Steinberg JM, Gatto LA, DiRocco JD, Pavone LA, Schiller HJ, et al. Effect of positive end-expiratory pressure and tidal volume on lung injury induced by alveolar instability. Crit Care 2007;11:R20.

4. Stewart TE, Meade MO, Cook DJ, Granton JT, Hodder RV, Lapinsky $\mathrm{SE}$, et al. Evaluation of a ventilation strategy to prevent barotrauma in patient at high risk for acute respiratory distress syndrome. Pressure- and Volume-Limited Ventilation Strategy Group. N Engl J Med 1998;338(6):355-361

5. Amato MB, Barbas CS, Medeiros DM, Magaldi RB, Schettino GP, Lorenzi-Filho G, et al. Effect of a protective-ventilation strategy on mortality in acute respiratory distress syndrome. N Engl J Med 1998; 338(6):347-354

6. The Acute Respiratory Distress Syndrome Network. Ventilation with lower tidal volumes as compared with traditional tidal volumes for acute lung injury and the acute respiratory distress syndrome. N Engl J Med 2000;342(18):1301-1308.

7. Serpa Neto A, Cardoso SO, Manetta JA, Pereira VG, Espósito DC, Pasqualucci MO, et al. Association between use of lung-protective ventilation with lower tidal volumes and clinical outcomes among patients without acute respiratory distress syndrome: a meta-analysis JAMA 2012;308(16):1651-1659.

8. Schultz MJ, Haitsma JJ, Slutsky AS, Gajic O. What tidal volumes should be used in patients without acute lung injury? Anesthesiology 2007;106(6):1226-1231

9. Needham DM, Colantuoni E, Mendez-Tellez PA, Dinglas VD, Sevransky JE, Dennison Himmelfarb CR, et al. Lung protective mechanical ventilation and two year survival in patients with acute lung injury: prospective cohort study. BMJ 2012;344:e2124.

10. Rubenfeld GD, Cooper C, Carter G, Thompson BT, Hudson LD. Barriers to providing lung-protective ventilation to patients with acute lung injury. Crit Care Med 2004;32(6):1289-1293.

11. Yilmaz M, Keegan MT, Iscimen R, Afessa B, Buck CF, Hubmayr $\mathrm{RD}$, Gajic O. Toward the prevention of acute lung injury: protocolguided limitation of large tidal volume ventilation and inappropriate transfusion. Crit Care Med 2007;35(7):1660-1666.

12. Restrepo R, Baram M, Marik P. Blood transfusion: who knows what to do? A survey of medical house-staff. Chest 2012;142(4):537A.

13. Wolthuis EK, Korevaar JC, Spronk P, Kuiper MA, Dzoljic M, Vroom MB, Schultz MJ. Feedback and education improve physician compliance in use of lung-protective mechanical ventilation. Intensive Care Med 2005;31(4):540-546.

14. Weinert CR, Gross CR, Marinelli WA. Impact of randomized trial results of acute lung injury ventilator therapy in teaching hospital. Am J Respir Crit Care Med 2003;167(10):1304-1309.

15. Eslami S, de Keizer NF, Abu-Hanna A, de Jonge E, Schultz MJ. Effect of a clinical decision support system on adherence to a lower tidal volume mechanical ventilation strategy. J Crit Care 2009;24(4): 523-529.

16. Pai MP, Paloucek FP. The origin of the "ideal" body weight equations. Ann Pharmacother 2000;34(9):1066-1069.

17. Hager DN, Krishnan JA, Hayden DL, Brower RG. Tidal volume reduction in patients with acute lung injury when plateau pressures are not high. Am J Respir Crit Care Med. 2005;172(10):1241-1245.

18. Young MP, Manning HL, Wilson DL, Mette SA, Riker RR, Leiter JC. Ventilation of patients with acute lung injury and acute respiratory distress syndrome: has new evidence changed clinical practice? Crit Care Med 2004;32(6):1260-1265

19. Eslami S, Abu-Hanna A, Schultz MJ, de Jonge E, de Kreizer NF. Evaluation of consulting and critiquing decision support systems: effect on adherence to a lower tidal volume mechanical ventilation strategy. J Crit Care 2012;27(4):42.

This article is approved for Continuing Respiratory Care Education credit. For information and to obtain your CRCE

(free to AARC members) visit www.rcjournal.com 